\title{
Modeling the Ecological-Socio-Economic System of the White Sea and its Watershed
}

\author{
V. V. Menshutkin ${ }^{1}$, N. N. Filatov ${ }^{2, 凶}$ \\ ${ }^{1}$ Institute for Regional Economic Studies, Russian Academy of Sciences, Saint Petersburg, \\ Russian Federation \\ ${ }^{2}$ Northern Water Problems Institute, Karelian Research Center, Russian Academy of Sciences, \\ Petrozavodsk, Russian Federation \\ 凶nfilatov@rambler.ru
}

Purpose. The work is aimed at developing a cognitive model of the ecological-socio-economic system of the White Sea (Beloe more) and its watershed (called for short Belomor'e). Unlike the previously developed cognitive models for the region, the new model of the system has a hierarchical structure including five sub-models united by a common management system. The model is intended for obtaining prognostic qualitative assessments of the transformations ongoing in a complex system under various scenarios of nature management and climate change. The model makes it possible to determine different targets, which, in their turn, permit to assess the possibilities of improving the population living standards, the environment rational use and protection, and development of the White Sea region social sphere. These factors constitute an important foundation for achieving sustainable development of the region. The results can serve a basis for constructing a system of quantitative models required to develop the management decision support systems.

Methods and Results. The cognitive model of the White Sea is considered to be a tool for synthesizing heterogeneous information about a complex ecological-socio-economic system. The conceptual modeling and the mathematical apparatus of continuous or probabilistic logic are applied. Unlike the traditional cognitive models, the new one implies the variables' change in time over 100 years. This allows us to describe the relationship between the interaction agents, and to characterize the mechanisms of their mutual adaptation. The time step in the model is preset to be one year. Development of the cognitive models for the White Sea region was supported by the following information: geographic information systems, databases, integrated electronic and paper atlases of the White Sea and its watershed area, original 3D mathematical models of the sea thermohydrodynamics and ecosystem. The patterns of climate change, hydrological conditions and fishing (basic occupation of local population - the Pomors) were studied. At that, the models both for assessing the regional economy state and for forecasting its development are used.

Conclusions. A new cognitive model of the White Sea region ecological-socio-economic system was created based on the hierarchical principle. The developed sub-models relate to various fields of knowledge: economy, demography, oceanography, soil and agrophysics. Dynamics of the model elements over 100 years was demonstrated. Besides, it was shown that with the quasi-cyclic climate fluctuations, the economic parameters change insignificantly, whereas they have a noticeable impact upon the population living standards and the White Sea ecosystem. The demonstrated features resulted from the climate change effects upon the White Sea ecosystem are manifested in the fluctuations of water temperature, phyto- and zooplankton biomass and fishing, but the changes in benthos are hardly noticeable. Dependence of the White Sea region population outflow upon the gross regional product size, availability of production facilities and water quality is shown. Water quality in the region increases, unfortunately, not due to the investments in water treatment, but because of the pollution decrease resulted from the population and production shrinkage.

Keywords: environment, population, economy, cognitive model, forecasting, climate, White Sea, watershed

Acknowledgments: the research was financially provided by the federal budget intended for implementing the state task to the Northern Water Problems Institute, Karelian Research Center, Russian Academy of Sciences and the Institute for Regional Economic Studies, Russian Academy of Sciences (AAAA-A19-119-021390164-1). The authors are grateful to T.R. Minina (IRES RAS) for her valuable assistance in preparing the article, L.E. Nazarova (NWPI, KarRC RAS) for her useful comments, and M.S. Bogdanova (NWPI, KarRC RAS) for her help in preparing the figures. 
For citation: Menshutkin, V.V. and Filatov, N.N., 2021. Modeling the Ecological-Socio-Economic System of the White Sea and its Watershed. Physical Oceanography, [e-journal] 28(1), pp. 104-121. doi:10.22449/1573-160X-2021-1-104-121

DOI: 10.22449/1573-160X-2021-1-104-121

(c) V. V. Menshutkin, N. N. Filatov, 2021

(C) Physical Oceanography, 2021

\section{Introduction}

The White Sea and its watershed (Belomor'e) is a region rich in water, biological, transport, energy and mineral resources. The White Sea watershed with of 717.7 thousand $\mathrm{km}^{2}$ makes up more than $10 \%$ of the Arctic zone of the Russian Federation, including a significant part of the territory of 7 constituent entities of the Russian Federation: Murmansk, Arkhangelsk, Vologda regions, the Republic of Karelia and the Republic of Komi, as well as a small part of the Kirov region and the Nenets Autonomous Okrug [1]. Until 1991, the White Sea was subject to severe pollution, fish and mineral resources were quite actively used, mariculture and water transport were developing. But after 1991, crisis phenomena in the socio-economic sphere began to be observed in Belomor'e region. One of these was depopulation - the population of the region decreased by more than 1 million people over 30 years, there was also a significant reduction in the volume of industrial fishing, fish and mariculture farming [2, 3].Complex processes in the socio-economic sphere of the region are caused not by the depletion of natural resources, but by the economy functioning peculiarities of the country's constituent entities, by the imperfection of the legislative framework governing economic and environmental activities. During the reform period of the 90 s of the $20^{\text {th }}$ century. there was a sharp decrease of investment to the region and of the GRP. The sea condition (water quality, fish resources) also affects the socio-economic processes characteristic for Belomor'e, and vice versa, the area in the watershed, having area 8 times larger than the White Sea, influence the its ecosystem.

The experience of studying complex ecological-socio-economic systems is available for the Black Sea and its coastal zone [4]. To describe the processes, a systematic approach, in which the economic goals of the consumption of biological resources were made dependent on the ecological state of the marine environment, was used. Examples of managing the balance of ecological-socioeconomic processes using integral biodiversity criteria of and the level of marine environment pollution were considered. Another approach to the study of socioeconomic systems using cognitive models was applied to assess the possibilities for sustainable development of the Black Sea, Caucasian and Caspian sub-regions [5]. In [6], the main impacts of climate on the geophysical parameters of the Arctic, directly and/or indirectly affecting the socio-economic processes in the Arctic (such as the extraction and exploitation of resources, living conditions of the population and transport), important for the sustainable development of its regions were estimated.

Cognitive models were developed to study the complex ecological-socioeconomic system the White Sea - watershed [7-9]. In the first cognitive models of 
such a system, the possibility of ensuring the best development of all subregions (constituent entities of the Russian Federation) included in the watershed for sustainable development of the region was considered as the principal target function [7]. The ratio of the investment amount in the development of subregions and the demographic characteristics of the population to achieve the best (comfortable) living conditions was assessed. In [8], a cognitive model to study the possibility of living standard raising of the population using fishing a traditional occupation of the local population - the Pomors, was developed. In the third model for this region [9], the multicriteria problem of determining a mode of control actions was solved. The mode obtained could provide the maximum standard of living of the population of the region under different scenarios of the economy and climate change state. Unlike previous developments, the new model of the ecological-socio-economic system of the White Sea and its watershed has a hierarchical structure, which includes 5 sub-models, united by a common management system. In the present paper, a model that represents the development of ecological and economic cognitive models [7, 10, 11] is proposed. It can be used for various management purposes, related, for example, to raising the living standard of the population, protecting the environment and developing various sectors of the economy.

\section{Materials and Methods}

The cognitive model of Belomor'e is considered as a tool for synthesizing heterogeneous information about a complex ecological-socio-economic system for the development of approaches that may be of interest for support system decision [12]. Conceptual modeling and mathematical apparatus of probabilistic logic are used [13, 14]. Unlike traditional cognitive models, the present one provides for a change in variables over time over 100 years, which permits to describe the relationship between the agents of interaction and to characterize the mechanisms of their mutual adaptation. The time step of the model is one year. For the climatic and socio-economic parts of the model, this value of the time step seems to be quite natural, but for the ecosystem part (since even seasonal changes are not considered), this is a rather rough approximation that must be taken into account to avoid excessive complication of the entire model.

From the electronic atlas, databases and the geoinformation system of Belomor'e developed at the Northern Water Problems Institute KarRC RAS $[15,16]$, constantly updated data were selected to characterize the climate (air temperature, precipitation and evaporation), river runoff and various socioeconomic parameters (GRP, investments, polluted water discharges, the number and composition of the population, fish catch, etc.), data for characterizing changes in the sea ecosystem (temperature and salinity of water, biogens, phyto- and zooplankton, etc.), obtained according to measurements and results of calculations on 3D-models of the ecosystem [1, p. 303-331; 17], as well as information for assessing the state and forecasting the development of the economy $[2,18]$.

All model variables are described using real numbers ranging from 0 to 1 . In essence, this is interpreted as a change in the modeled value between its possible maximum and minimum values. For example, the water surface temperature in 106

PHYSICAL OCEANOGRAPHY VOL. 28 ISS. 1 (2021) 
the White Sea does not go beyond the range of $-1 \ldots+25{ }^{\circ} \mathrm{C}[5]$, and the population of Belomor'e, according to estimates [18], can hypothetically range from zero to six million people.

The first cognitive model for Belomor'e [7] considered changes in the hydrological conditions of the ecosystem, biogenic load, phyto- and zooplankton, and fish stocks. Under the inertial scenario of economic development, which provides for the preservation of external impacts on the system, as they were until 2018, the stabilization of the sea pollution level and the preservation of fish resources is noted. But with a significant increase in investment in the region, along with an increase in GRP, the volume of pollution entering the sea increases and the volume of fish resources goes down. In the water ecosystem model, the processes of organic matter production and its transfer along the trophic network of the waterbody to the level of the biomass of the population of commercial fish in the sea are presented.

The controlling impact of the climate on the White Sea system includes a description of variations in the mean annual air temperature, the volume of atmospheric precipitation, evapotranspiration and the total mean annual river runoff into the White Sea [19].

Indeed, the definition of the state of the cognitive model concepts ranging from 0 to 1 allows considering them as probabilities of some events [20]. The cognitive modeling method used in this study is based on a probabilistic model [21]. For example, in the Water ecosystem sub-model (Fig. 1), the condition of the fish age group is determined by the younger group condition in the previous year and by the processes of mortality and growth. Since the probability of the fish group existence and the probability of survival are compatible events, the formula for multiplying the probabilities is applied. The use of the mathematical apparatus of probabilistic logic makes the process of creating and program interpretation of the model simpler.

Cognitive modeling has specific properties that should be taken into account both when creating models and when assessing the results obtained. Unlike traditional ecosystem models [22], cognitive models do not use the principles of conservation laws. This applies not only to the laws of conservation of matter and energy in models of water and soil media or biological objects, but also to economy. This fact, of course, impoverishes the possibilities of cognitive modeling, although it permits to consider a combination of objects of different nature as a unit, as is done in the present paper.

The model functioning starts with setting the climatic conditions variations for the entire period of its operation, that is, for 100 years, starting from 1960, captures a fairly well-studied state of the entire system and provides an opportunity to move to predicting possible states of the ecological-socio-economic system of Belomor'e.

The model has a hierarchical structure that includes 5 sub-models united by a common control system (Control) (Fig. 1). 


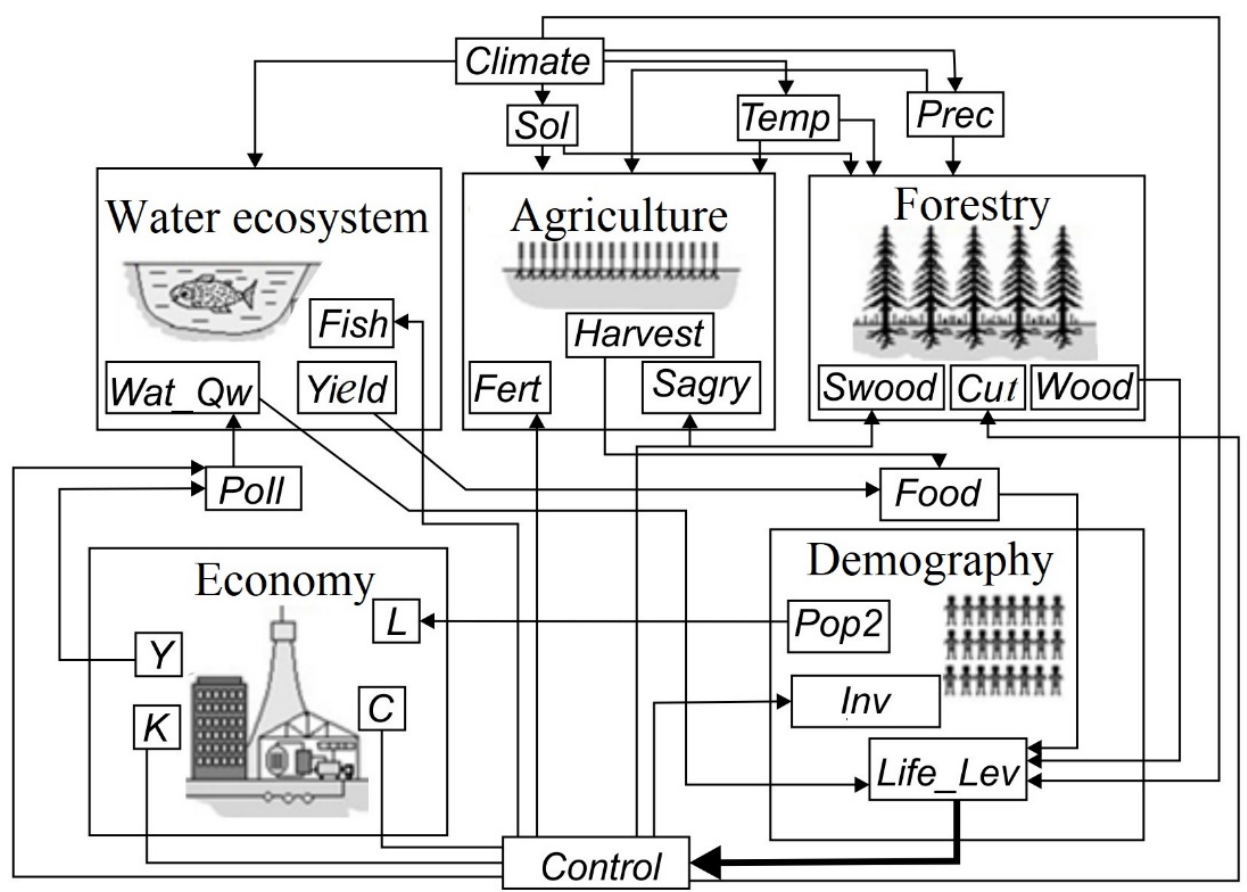

F i g. 1. General block diagram of the regional ecological-socio-economic model: $Y$ - gross regional product; $K$ - capital or production facilities; $L$ - number of working population; $C$ - consumption; Inv - investment. The other conventions are given in the text

The sub-model of Economy is designed to determine the GRP (further denoted as $Y$ ) and the associated costs of the wastewater treatment process in the region (Poll) - an important indicator of the environment state. GRP is also spent on ensuring a certain standard of living of the population (Life_Lev) and on related subsystems - fishing (Fish), fertilization for agricultural development (Fert) and domestic needs, such as the cost of developing production assets $(K)$.

The sub-model of Demography provides the sub-model of Economy with the data on the size of the population, especially of the able-bodied population aged 18-60 years $(L)$. In this sub-model, the living standard of the population (Life_Lev) is determined, the value of which is the objective function of optimal control of the entire system under study.

The sub-model of Water Ecosystem is responsible for imitating the processes of organic matter production and its transfer through the waterbody food web to the level of the biomass of the commercial fish population in the sea. Consider herring and navaga as the main commercial species of the White Sea [3]. Their populations under the influence of fishing (Fish) provide a certain catch (Yield), which is a component of the population's nutrition (Food). The state of water ecosystems depends on climate change (Climate) and waterbody pollution with industrial and domestic waste (Poll). The water quality of the waterbody (Wat_Qw) significantly affects the standard of living of the region's population (Life_Lev). 
The sub-model of Agriculture generates data on agricultural activities in the region, in particular, determines the volume of the harvest (Harvest). The state of agriculture, or agrosystems, just like forestry, is determined by climate (solar radiation (Sol)), air temperature (Temp) and precipitation (Prec). An essential characteristic of the sub-model is the size of the area occupied by agricultural land (Sagry), which is in competition with the area occupied by forests and settlements in the region.

The sub-model of Forestry generates information on the forest system response to changes in climatic conditions (Sol, Temp, Prec), on the cutting intensity (Cut), environmental pollution (Poll) and the reduction of forest areas under the influence of agricultural development and the expansion of the area of urbanized territories (Swood).

The control unit for the entire system (Control) is aimed in this case at improving the living standards of the population (Life_Lev) by investing in industry, agriculture and forestry, fishing and fish farming and in environmental activities.

As a sub-model of Economy, the Solow - Swan model was chosen, which is a neoclassical model of economic growth proposed by Robert Solow [see. 23]. It is based on the production function of Cobb - Douglas and shows the dependence of the volume of production on the factors of production creating it - labour and capital [23]. In this case, a variant with discrete time is used, and the modelling algorithm is made in the form of a cognitive model. Cognitive graph of the submodel of Economy sub-model is shown in Fig. 2.

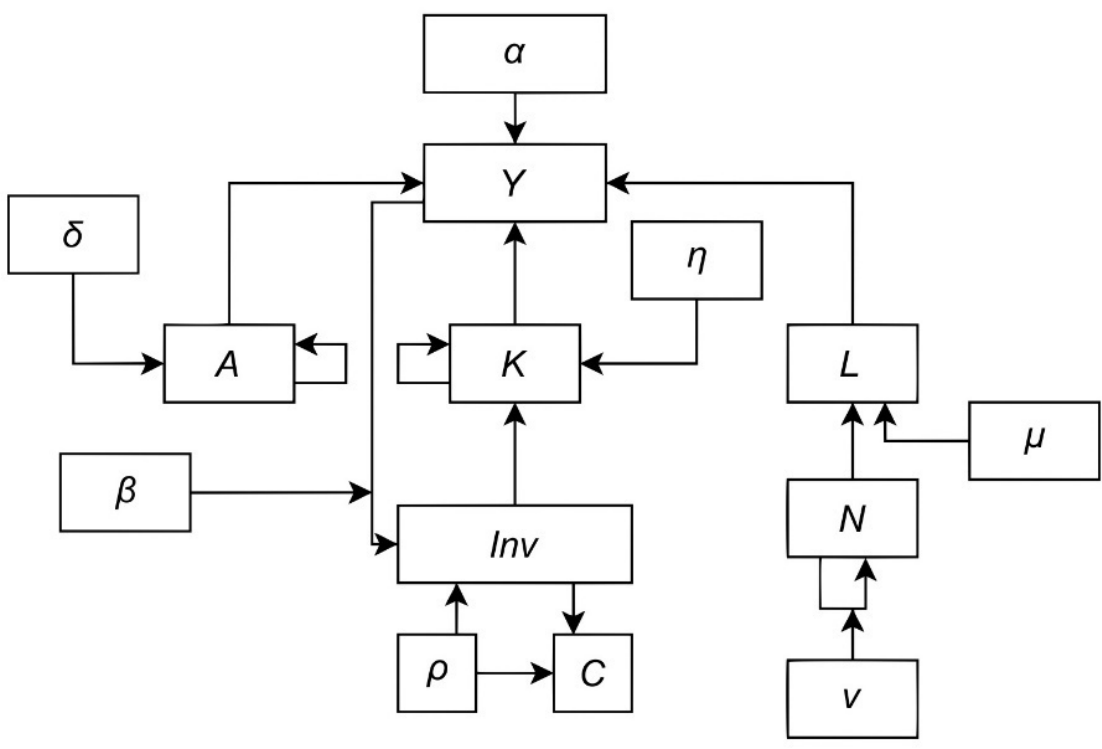

F i g. 2. Cognitive graph of the sub-model Economy: $Y$ - gross regional product; $A$ - level of technological progress; $K$ - capital or production facilities; $L$ - number of working population; $N$ number of population; $C$ - consumption; $\alpha$ - portion of capital in the Cobb-Douglas formula; $\beta$ coefficient of direct costs; $\delta$ - coefficient of technological progress; $\eta$ - depreciation coefficient of funds; $\rho$-accumulation rate; $\mu$ - portion of the working population; $v$ - population growth rate 
The population size at time $t+1$ is determined based on its size at the previous time $t$ and coefficient $v$ according to the ratio of logistic growth:

$$
N(t+1)=N(t)+v N(t)(1-N(t)) .
$$

Labor force, or the number of the working population, at full employment is calculated as a fraction $\mu$ of the total population:

$$
L(t)=\mu N(t) .
$$

Level of technical progress is assumed to be increasing depending on the coefficient of technical progress $\delta$ :

$$
A(t+1)=A(t) \delta A(t)(1-A(t))
$$

The production function, which is the dependence of the produced product $(Y)$ on production assets $(K)$, labor $(L)$ and the level of technological progress $(A)$, was determined by the Cobb-Douglas formula [23]:

$$
Y(t+1)=A(t) L(t)^{\alpha} K(t)^{(1-\alpha)},
$$

Where $\alpha$ is the share of capital in the process of creating products.

Alternatively, instead of the Cobb-Douglas formula in the model, the V. Leontiev's formula, which is the V. Leontiev's production function with constant consumption proportions [23], can be applied:

$$
Y(t+1)=\min (K(t), A(t) L(t)) .
$$

Part of the production was defined as direct costs (coefficient $\beta$ ), and the remaining part was used for investments for capital replenishment (Inv) and consumption $(C)$. At the same time, the share of investment in production assets $(K)$ was regulated by the coefficient $\rho$ :

$$
\begin{gathered}
\operatorname{Inv}(t+1)=\rho(1-\beta) Y(t+1), \\
C(t+1)=(1-\rho)(1-\beta) Y(t+1) .
\end{gathered}
$$

Value of production assets at the next moment in time increased due to investments (Inv), but decreased due to depreciation (coefficient $\eta$ ). An increase in the rate of depreciation of production assets leads to a reduction of production:

$$
K(t+1)=(K(t)+\operatorname{Inv}(t+1)-K(t) \operatorname{Inv}(t+1))(1-\eta) .
$$

Here's an example of the functioning of the sub-model of Economy (Fig. 3, a): under constant external influences (increased investment, favorable climate, etc.), an increase in the population, especially the able-bodied population $(L)$, there is an increase in the level of technological progress $(A)$ with an increase in consumption $(C)$; at the same time, there is a not very significant increase in the gross regional product $(Y)$, investments (Inv) from 0.1 to 0.4 , but in general, the dynamics of economic development $(F)$ will get a significant increase over 100 years - from 0.1 to 0.8 . 

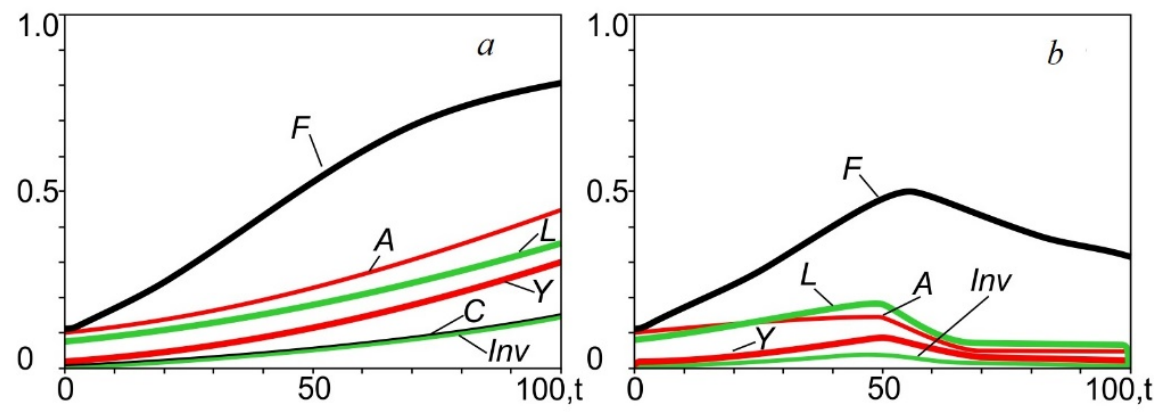

F i g. 3. Dynamics of the economical development $(F)$ in view of the population and technological progress growth (a), and - the population and technological progress level decrease since $\boldsymbol{t}=50$ and with subsequent stagnation at $\boldsymbol{t}=50$ years $(b)$ : $A$ - technological progress level; $L$ - number of working population; $Y$ - gross regional product; Inv - investment; $C$ - consumption; $t$ - time (years)

With a population and investment in the region, the level of technical progress also goes down, and at $t=50$ years, there is a sharp decline in the development of the regional economy from 1 (at the first stage) to 0.5 in 50 years. Further, there is a drop from 0.5 to 0.3 of the economic development of the region as a whole at the end of the 100-year period (Fig. 3, b).

Below the sensitivity coefficients as a GRP $(Y)$ function to the change in the model parameters $(\rho)$ are shown. Maximum positive effect on the economy is made by an increase in the share of capital $(\alpha)$ in the expression of the production function; the population growth rate $(v)$ is of lesser importance:

$\begin{array}{lcccccc}\mu & v & \beta & \rho & \alpha & \delta & \eta \\ 0.764 & 0.548 & -0.088 & 0.66 & 0.708 & -0.05 & 0.099\end{array}$

Similar studies were carried out to ensure the consistency of the sub-model behavior before it is included in the complete model of the ecological-socioeconomic system.

Prototype of the sub-model of Demography, used in the present work, was the megalopolis development model [22, p. 334-347] with some of our changes for integration with other sub-models of the system. Fig. 4 shows the cognitive graph of the sub-model Demography (Popul).

The model condition is determined by the relative size of the group of people under the age of 18 (Pop1), the size of the working population of 18-60 years. (Pop2), and the number of elderly people over 60. Age structure of the population is represented in the sub-model by an array of the relative number of age groups of 0-80 years.

Gender division of the population is not taken into account in the model. The annual addition of the zero-age group Birth ( $t$ ) is determined by the size of the reproductive part of the population (Рop2) and the birth rate, which was assumed to depend (rather conditionally) on investment in the healthcare system (Inv_Life). The mortality rates were determined separately for each age group (M1, $M 2, M 3)$, with the minimum mortality rate for the group under 18 and the maximum - for the group over 60 . Mortality rates were adjusted by the general standard of living of the population (Life_Lev), and its quantitative assessment 
seems to be a very difficult to achieve [23-25]. Living standard decreases with high population and low investment in the region, and also when the water quality is poor. The proposed algorithm for calculating the value (Life_Lev) will be considered no more than a first approximation. The arguments for the sought function are: total population (Popul), investment in health (Inv_Life), water quality (Wat_Qw), climatic conditions (Climate), fraction of the surface occupied by untouched nature, characterizing the state of the environment (Wood), and total environment pollution (mainly water) (Poll). And vice versa, untouched nature, good climate (for the North, its modern warming will be considered as such) increase the value (Life_Lev).

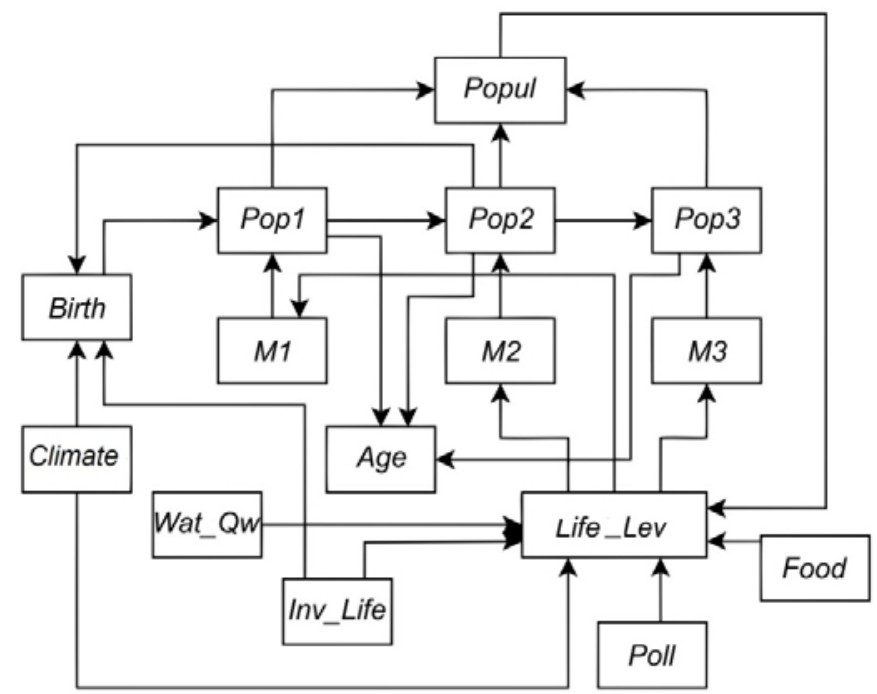

F i g. 4. Cognitive graph of the sub-model Demography: Pop1- population under 18, Pop2 population from 18 to 60, Pop3- population over 60; Birth - birthrate, M1- mortality rate of population under 18, $M 2$ - of population from 18 to $60, M 3$ - of population over 60; Age - population average age; Climate - climatic conditions; Wat_Qw - water quality; Inv_Life - health care investment; Poll - environment pollution; Food - food stuffs

The mean life expectancy (Life) is calculated as

$$
\text { Life }=\frac{1}{a(0)} \sum_{i=1}^{80}(a(i-1)-a(i)) i+a(80) 80 .
$$

The mean age of the population (Age) is determined by the following formula

$$
\text { Age }=\frac{\sum_{i=0}^{80} a(i) i}{\sum_{i=0}^{80} a(i)} .
$$

Age composition of population corresponds to a stationary state with external impacts constant over time. Changes in population age structure are also 
considered with periodic quasi-sinusoidal changes in investment and a sharp change in environmental conditions, at the initial stage of fertility decline at $\boldsymbol{t}=40 \mathrm{~s}$, followed by stabilization, starting from $t=60$.

The sub-model of Water Ecosystem in this case, is represented by one population of commercial fish, consisting of 6 age groups, and, as in the model [7], by values characterizing the biomass of benthos, phyto- and zooplankton. The importance of including fishing in the model is due to the fact that it significantly affects the living conditions of the local population - the Pomors of the White Sea region. The sub-model is based on models of ecosystems, which took into account the principles of conservation of matter and energy; these models were developed earlier for more complex objects, for example, for Lake Ladoga and the Gulf of Finland [22]. Fig. 5 shows the cognitive graph of the sub-model.

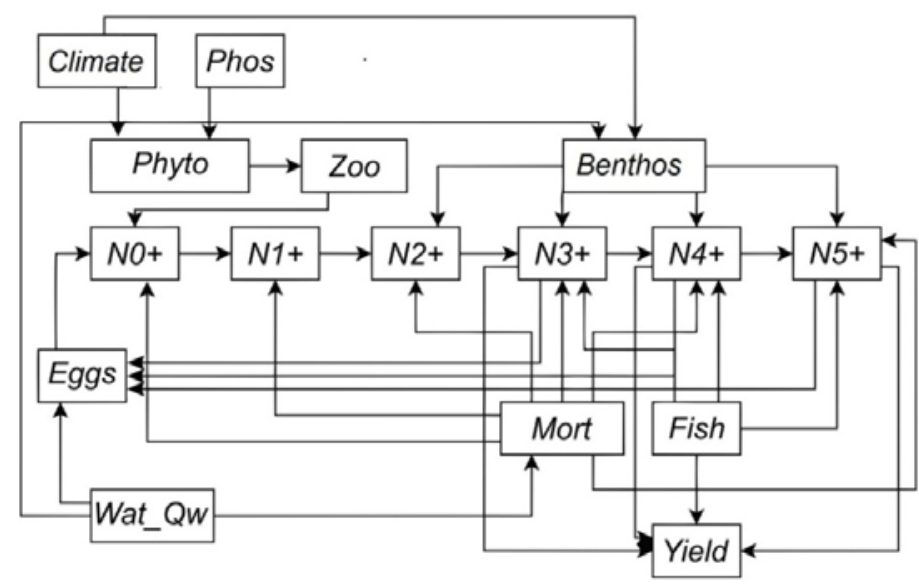

F i g. 5. Cognitive graph of the sub-model Water ecosystem: Climate - climatic conditions; Phos phosphorus load; Phyto - phytoplankton production; Zoo- zooplankton biomass; Benthos - benthos biomass; $\mathrm{NO}+$ - yearlings; $N 1+$ - yearlings; $N 2+-$ two-year-olds; $N 3+-$ three-year-olds; $N 4+-$ fouryear-olds; $N 5+$ - five-year-olds; Eggs - caviar replenishment; Mort - natural mortality; Fish - fishing conditions; Wat_Qw - water quality; Yield - fish catch

The primary production of phytoplankton (Phyto) is assumed to depend on the solar radiation, represented in the model by the variable Climate, and the concentration of nutrients (Phos) with the imitation of Liebig's law using the conjunction operation in probabilistic logic. The biomasses of zooplankton (Zoo) and benthos (Benthos) as food resources for commercial fish are defined as links in the food chain, and it is assumed that the development of benthos is negatively affected by deterioration in water quality (Wat_Qw). Age groups of the commercial fish population ( $N 0, N 1, N 2, N 3, N 4$ and $N 5)$ are interpreted as biomass.

Moreover, the growth rate of fish is assumed to be constant over time. We believe that the fish of the two younger age groups feed on zooplankton, the older ones - on benthos. The spawning herd of the population is formed from individuals of the three older age groups. The gender ratio is considered constant and is not taken into account in the model. The success of reproduction is significantly influenced by water quality (Wat_Qw). The same applies to 
the natural mortality of fish, which is assumed to be the same for all age groups. In addition to natural mortality, the three older age groups are influenced by fishing, which is associated with fishing conditions (Fish). Fishing (Yield) is influenced by two factors: the availability of fish in the harvested age groups ( $N 3$, $N 4, N 5$ ) and the fishing conditions. With a total catch of fish, the subsequent catch will be zero.

The sub-model of Forestry is constructed on the basis of models developed earlier for the waterbody-watershed system [26, 27]. The variables that determine the state of the system are the biomass of trees (Biom), the mass of organic matter in the litter and soil (Organic), and the content of mineral nitrogen in the soil (Ndep). The cognitive graph of the sub-model is shown in Fig. 6.

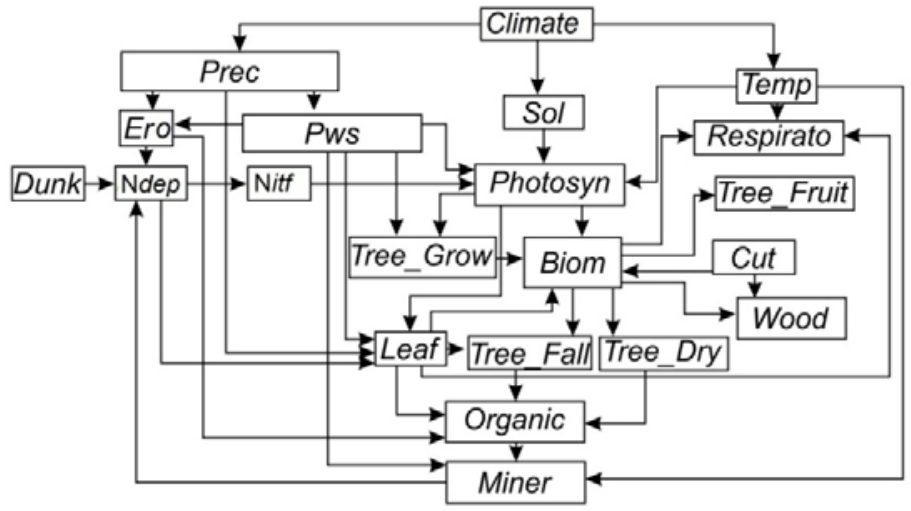

F i g. 6. Cognitive graph of the sub-model Foresty: Climate - climatic conditions; Prec precipitation; Sol - solar radiation; Temp - air temperature; Ero - soil erosion; Pws - lack of moisture; Respirato - respiration; Dunk - soil nitrogen application; Ndep - soil nitrogen reserves; Nitf - soil nutrient reserves; Photosyn - photosynthesis rate; Tree_Grow - growth of trees; Tree_Fall - leaf fall; Tree_Dry - drying; Tree_Fruit - fruits (apples etc.); Leaf - mass of leaves; Cut - cutting intensity; Biom - biomass; Wood - wood export; Organic - organic matter volumes; Miner - bacterial mineralization

Below a relatively simplified scheme of the sub-model of Forestry is considered. Change of biomass is generally determined by the growth of wood pulp (Tree_Grow) (excluding the mass of leaves (Leaf), which are assumed to fall annually), the cost of tree death due to slower growth (Tree_Fall) and the lack of water necessary for tree growth (Tree_Dry). Wood pulp growth is determined by the difference between photosynthesis (Photosyn) and respiration (Respirato). Photosynthesis depends on solar radiation ( $\mathrm{Sol}$ ), the presence of nutrients in the soil (Nitf), moisture deficit ( $P w s$ ) and the mean air temperature during the growing season (Temp). Respiration rates of trees depend on their biomass (Biom), leaf mass and temperature conditions. The leaf mass is assumed to depend on the biomass of the trees.

The organic matter of both leaf litter and soil (Organic) is formed by falling leaves and the death of wood (Tree_Fall and Tree_Dry). The first component is determined by unfavorable conditions of the stand state with a slowdown in growth and an increase in forest biomass above the limit values, the second component is determined by a moisture deficit $(P w s)$. Organic matter is decomposed by bacteria (Miner) and washed away by erosion (Ero). Intensity of organic matter 
mineralization depends on the water content in the soil and temperature conditions. Insufficient soil moisture or excess moisture slows down the process of organic mineralization. Intensity of erosion processes is assumed to depend on the amount of atmospheric precipitation (Prec). Mineral nitrogen contained in the soil is replenished by mineralization of organic matter and external inputs from precipitation, nitrogen fixation and artificial fertilization (Dunk). In addition, mineral nitrogen is removed from the soil as a result of surface and ground runoff, as well as in the process of soil erosion (Ero).

Let us calculate the dynamics of the total biomass (Biom), litter (Organic), nitrogen in the soil (Ndep) and timber evacuation (Wood) both undermean values of all the impacts and with weakening of solar radiation, no deforestation and a decrease in moisture supply to the watershed. Under all values of all the impacts, a stable change in all parameters is noted, starting from the second year of the system operation and with a solar radiation decrease in the $5^{\text {th }}$ year, the nitrogen content in the soil slightly increases and then gradually stabilizes over time. In the absence of deforestation, a high content of the total biomass and biomass of litter is evidently retained at a sufficiently low nitrogen content in the soil. And, finally, with a decrease in the input of moisture to the watershed, periodic fluctuations of the organic matter biomass in litter and, starting from the $5^{\text {th }}$ year, stably low values of the total biomass, nitrogen content in the soil are observed. Moreover, at the same time, there are low opportunities for timber extraction and evacuation.

The sub-model of Agriculture developed on the basis of the Agritool system, previously created by the authors from the Agrophysical Institute [28]. However, in the present model, significant simplifications were carried out for the studied region, due to the need to dock this block with other sub-models in the system. For example, the Agritool system [28] operates with daily and even hourly time steps.In this model an annual step is adopted (Fig. 7).

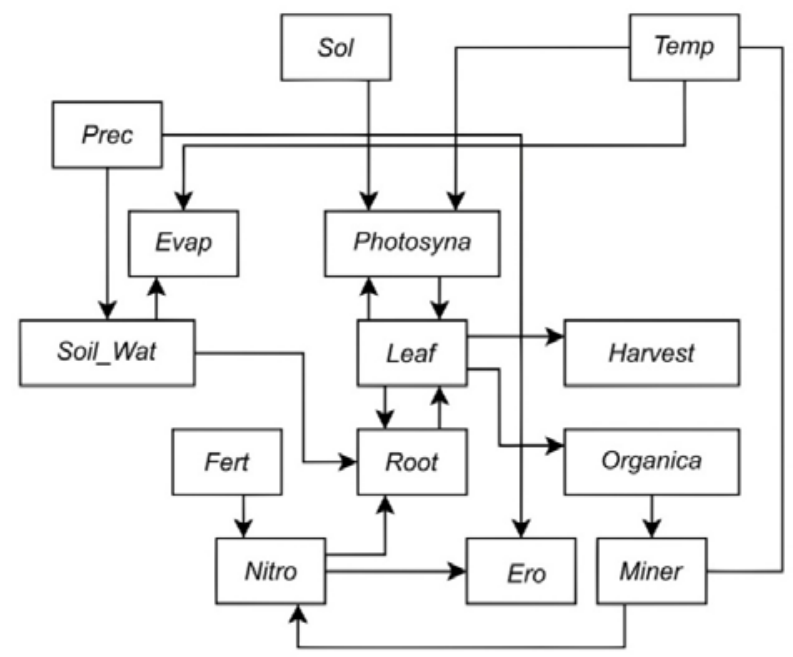

F i g. 7. Cognitive graph of the sub-model Agriculture: Sol - solar radiation; Temp - temperature; Prec - precipitation; Evap - evaporation; Photosyna - photosynthesis; Leaf - terrestrial part of plants; Soil_Wat - water in soil; Harvest - harvest; Fert - fertilizer; Root - tree roots; Organica - litter; Nitro - nitrogen in soil; Ero - soil erosion; Miner - bacterial mineralization 
Process of photosynthesis (Photosyna) is the basis creating the biomass of agricultural plants. The letter "a" at the end of this identifier is added to distinguish it from the same value in the sub-model of Forest Ecosystem. The calculation applies Liebig's law of minimum, corrected for temperature:

$$
\text { Photosyna }=\min (\text { Sol, Leaf }) F(\text { Temp }) \text {. }
$$

Here, the leaf biomass (Leaf) plays the role of a limitation on the availability of nutrients, which increases due to nutrition from the roots (Root) and decreases because of drying out. The root system growth occurs due to the inorganic nitrogen absorption in the soil (Nitro). Dead organic matter (Organica) is formed due to the death of the terrestrial part of plants and is mineralized (Miner) because of the activity of soil microorganisms with the inorganic nitrogen release. This nitrogen supply is replenished by fertilization (Fert) and is reduced by soil erosion (Ero). Atmospheric precipitation (Prec) significantly affects the erosion process rate.

Evaporation from the soil surface (Evap) is assumed to depend on air temperature (Temp), soil moisture (Soil_Wat) is determined by atmospheric precipitation and evaporation, yield (Harvest) - the biomass of the leaf part of plants (Leaf) achieved during the growing season.

\section{Coefficients of the Agriculture sub-model variables' sensitivity (flexibility) to modification of the external impacts (Sol, Prec, Fert, Temp)}

\begin{tabular}{l|c|c|c|c}
\hline \multicolumn{1}{c|}{ Variables } & Sol & Prec & Fert & Temp \\
\hline Harvest & 0.49 & 0.87 & 0.34 & 0.78 \\
Organica & 0.56 & 0.93 & 0.37 & 0.87 \\
Nitro & 0.0 & 0.10 & 0.51 & 0.27 \\
Root & 0.0 & 0.0 & 0.50 & 0.67 \\
Photosyna & 0.92 & 0.88 & 0.87 & 0.98 \\
Miner & 0.42 & 0.83 & 0.83 & 0.83 \\
\hline
\end{tabular}

According to the table data, it can be concluded that in the studied case, with average values of all external impacts on the agrocenosis, the amount of precipitation and air temperature has the greatest effect on the harvest.

\section{Results of studying the dynamics of the ecological-socio-economic system of Belomor'e}

The 5 sub-models considered above were combined into one system. All the sub-models operate in a single time cycle (100 years), and data transfer from one sub-model to another is carried out according to the arrows in Fig. 1. 
Fig. 8 shows the dynamics of model elements over 100 years with sinusoidal 30 -year (time scale of the climatic norm) fluctuations in climatic conditions (Climate $(t)=0.2+0.8(1+\sin (0.2 \mathrm{t})) / 2)$, determined by the parameters Temp, Sol and Prec. Moreover, all other external impacts are assumed to be constant in time. Climate fluctuations practically do not affect the economic part of the system in the considered model; there are no noticeable quasi-periodic 30-year fluctuations (Fig. 8, a). At the same time, in the sub-model of Demography (Fig. 8, b), climate fluctuations have a noticeable effect on the populationliving standard, which experiences quasiperiodic 30-year fluctuations.

The same noticeable fluctuations are noted in the water ecosystem, they are manifested in fluctuations in the fishcatch, phyto- and zooplankton (Fig. 8, c). However, this is not typical for benthos. In the parameters characterizing agriculture (Fig. 8, $d$ ), there are no noticeable manifestations of these climatic fluctuations. Only years with minimum mean annual air temperature are unfavorable for the harvest.

Assessment of the problems of population outflow from the region, typical not only for Belomor'e, but also for some regions of the North and the Far East of Russia, can bean example of the considered model application [29]. Fig. 9 shows the consequences of changes in the population of Belomor'e at certain GRP production assets and water quality values.
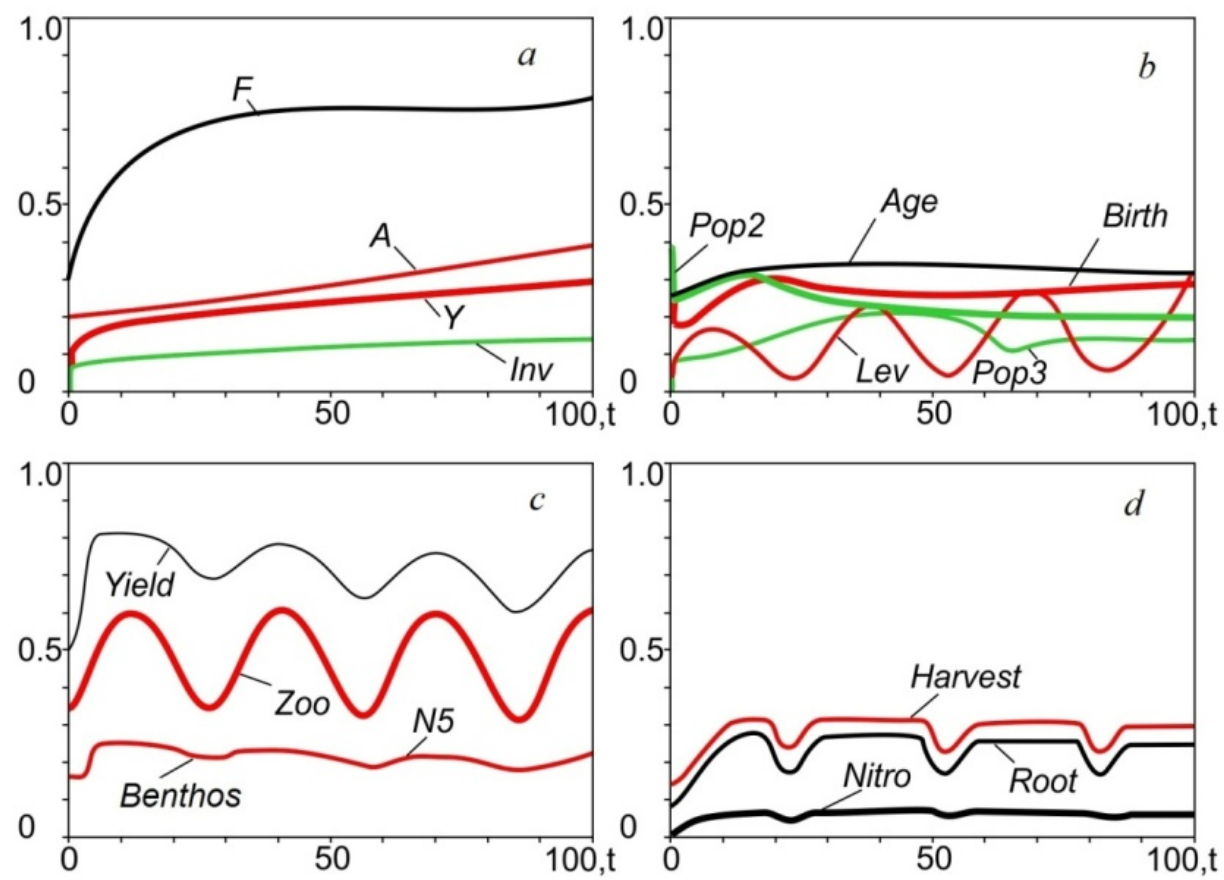

F i g. 8. Influence of the region system characteristics upon the sinusoidal changes in the climatic conditions. Sub-systems: $a$-Economy; $b$ - Demography; $c$ - Water ecosystem; $d$ - Agriculture 


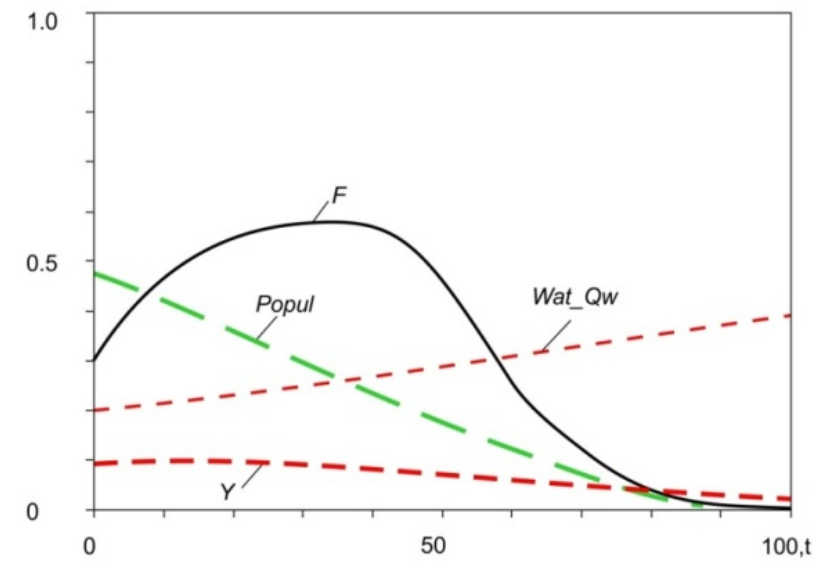

F i g. 9. Temporal changes of population (Popul), gross regional product $(Y)$, production facilities $(F)$ and water quality (Wat_Qw)

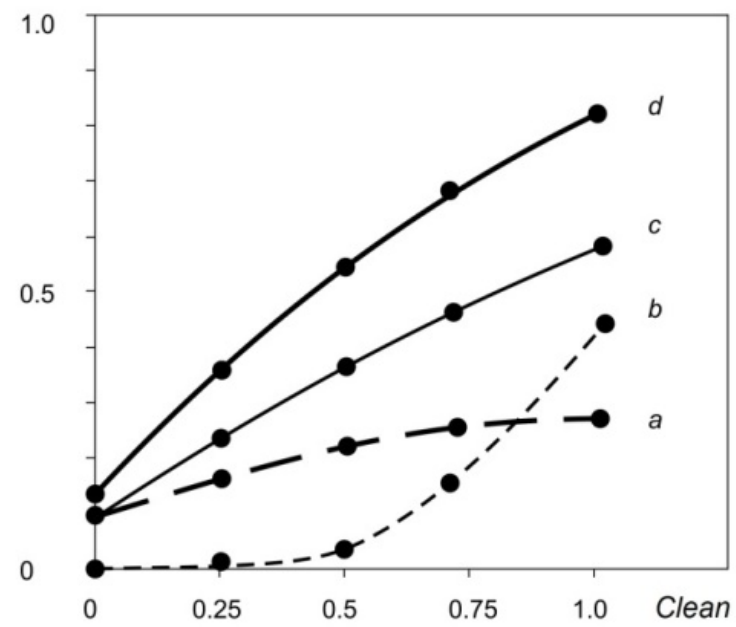

F i g. 10. Dependence of some system characteristics on the degree of wastewater treatment (Clean): level of the population living standards $(a)$, fish catch $(b)$, crop harvest (c), water quality $(d)$

If the GRP volume shows a tendency to decline, then production assets will grow for some time due to previous accumulations, but then begin to decline as a result of depreciation. Water quality slightly improves, not as a result of investment in water purification, but as a result of less pollution while reducing production. In the final analysis, the population in this situation tends to zero (Fig. 9).

Among the control actions on the system, in addition to the climate, the degree of industrial and domestic wastewater purification (Clean) is of significant importance. Fig. 10 shows the reaction of some system characteristics to a change in this value - from Clean $=0$ (complete rejection of wastewater treatment) to Clean $=1$ (complete cleaning). A rather obvious consequence of this change is an increase in the water quality indicator (Fig. 10) with a purification degree 
increase. The considered impact has the strongest effect on the commercial fish catch (Yield).

With a weak water purification, the fish catch increases almost exponentially: from 0 with a purification equal to 0.25 , to 0.5 with a complete water purification, but not to the unity element. Without water purification in the watershed, the fish population eventually ceases to exist. At the same time, the population living standard, even with complete purification, starts growing for some time, and then reaches a stationary mode, without reaching 0.5 (Fig. 10).

\section{Conclusion}

A new cognitive model of the White Sea region ecological-socio-economic system was created based on the hierarchical principle. The developed sub-models relate to various fields of knowledge: economy, demography, oceanography, soil and agrophysics. Functioning features of each of the 5 sub-models are considered. Dynamics of the model elements over 100 years was demonstrated. Besides, it was shown that with the quasi-cyclic climate fluctuations, the economic parameters change insignificantly, whereas they have a noticeable impact upon the population living standards and the White Sea ecosystem. The demonstrated features resulted from the climate change effects upon the White Sea ecosystem are manifested in the fluctuations of water temperature, phyto- and zooplankton biomass and fishing, but the changes in benthos are hardly noticeable. Agriculture in the watershed is rather weakly dependent on climate change. Dependence of the White Sea region population outflow upon the gross regional product size, availability of production facilities and water quality is shown. Water quality in the region increases, unfortunately, not due to the investments in water treatment, but because of the pollution decrease resulted from the population and production shrinkage. The study of the created model does not end with the examples given, as it is possible to search for optimal impacts on the system to maximize the living standards of the population.

\section{REFERENCES}

1. Filatov, N.N. and Terzhevik, A.Yu., Eds., 2007. The White [Beloe] Sea and their Watershed under Influenses of Climate and Antropogenic Impact. Petrozavodsk: KRC RAS. 335 p. (in Russian).

2. Druzhinin, P.V., Filatov, N.N., Moroshkina, M.V., Derusova, O.V., and Potasheva, O.V., 2018. Modeling and Spatial Analysis of Ecological and Economic Condition of the White Sea Reservoir. Proceedings of the International Conference "InterCarto. InterGIS", 24(1), pp. 130-142. doi:10.24057/2414-9179-2018-1-24-297-309 (in Russian).

3. Stasenkov, V.A., 2016. Fishing of Navaga Eleginus Nawaga (Koelreuter, 1770). The Bulletin of Fisheries Science, 3(2), pp. 18-26 (in Russian).

4. Timchenko, I.E., Ivashchenko, I.K. and Igumnova, E.M., 2017. Management of EcologicalEconomic Processes of Pollution Accumulation and Assimilation in the Coastal Zone Marine Environment. Physical Oceanography, (1), pp. 68-83. doi:10.22449/1573-160X-2017-1-68-83

5. Gorelova, G.V. and Ryabtsov, V.N., 2012. Cognitive Approach to the Research of Geopolitical Processes in World Regions and Cognitive Modeling of their Development (on the Example of the Black - Caspian Region). Engineering Journal of Don, 4(2), 90 (in Russian).

6. Crépin, A.-S., Karcher, M. and Gascard, J.-C., 2017. Arctic Climate Change, Economy and Society (ACCESS): Integrated Perspectives. Ambio, 46(Suppl. 3), pp. 341-354. doi:10.1007/s13280-017-0953-3 
7. Menshutkin, V.V., Filatov, N.N. and Druzhinin, P.V., 2018. A Current State and Forecasting of the Socio-Ecological-Economic System of the White Sea Watershed with Use of Cognitive Simulation. Arctic: Ecology and Economy, (2), pp. 4-17. doi:10.25283/2223-4594-2018-2-417 (in Russian).

8. Menshutkin, V.V. and Filatov, N.N., 2019. Cognitive Modeling of the Fisheries Effect on the Standard of Living in the White Sea Area. Transactions of the Karelian Research Centre of the Russian Academy of Sciences, (9), pp. 145-154. doi:10.17076/lim1120 (in Russian).

9. Menshutkin, V.V. and Filatov, N.N., 2020. Modeling Optimal Control of the EcologicalSocioeconomic System Water Body-Watershed: Case Study of the White Sea Region. Water Resources, 47(3), pp. 506-515. doi:10.1134/S0097807820030100

10. Menshutkin, V.V. and Minina, T.R., 2018. Cognitive Modeling as a Research Tool of Ecological and Economic Systems. In: L. P. Sovershaeva, Ed., 2018. Regional'naja Jekonomika i Razvitie Territorij [Regional Economy and Development of Territories]. Saint Petersburg: SUAI. Issue 1(12), pp. 157-163 (in Russian).

11. Menshutkin, V.V. and Minina, T.R., 2017. Cognitive Model of the Interaction of Human Society with the Ecological System of the Reservoir. In: L. P. Sovershaeva, Ed., 2017. Regional'naja Jekonomika i Razvitie Territorij [Regional Economy and Development of Territories]. Saint Petersburg: SUAI. Issue 1(11), pp. 160-166 (in Russian).

12. Ross, D., 2005. Economic Theory and Cognitive Science: Microexplanation. London: MITPress, $454 \mathrm{p}$.

13. Pavlov, S.N., 2011. [Artificial Intelligence Systems]. Tomsk: Electronic Content, 176 p. (in Russian).

14. Kosko, B., 1993. Fuzzy Thinking. New York: Hyperion, 318 p.

15. Chernov, I.A., Tolstikov, A.V. and Iakovlev, N.G., 2016. Comprehensive Model of the White Sea: Hydrothermodynamics of Water and Sea Ice. Transactions of the Karelian Research Centre of the Russian Academy of Sciences, (8), pp. 116-128. doi:10.17076/mat397 (in Russian).

16. Filatov, N.N., Tolstikov, A.V., Bogdanova, M.S. and Menshutkin, V.V., 2014. Development of Information System and Electronic Atlas on the State and Use of Resources of the White Sea and Its Catchment. Arctic: Ecology and Economy, 3(15), pp. 18-29 (in Russian).

17. Filatov, N.N., Druzhinin, P.V. and Menshutkin V.V., 2019. Information Support of Investigations of Environment and Socio-Economic Conditions of White Sea and Watershed. InterCarto. InterGIS. GI Support of Sustainable Development of Territories: Proceedings of the International Conference, 25(1), pp. 122-137. doi: 10.35595/2414-9179-2019-1-25-122137

18. Walliser, B., 2008. Cognitive Economics. Berlin: Springer-Verlag, 185 p. doi:10.1007/978-3540-71347-0

19. Filatov, N.N., Nazarova, L.E. and Druzhinin, P.V., 2019. Influence of Climatic and Anthropogenic Factors on the White Sea - Catchment System. Transactions of the Karelian Research Centre of the Russian Academy of Sciences, (9), pp. 30-50. doi.org/10.17076/lim1117 (in Russian).

20. Freiberger, W. and Grenander, U., 1971. A Course in Computational Probability and Statistics. New York: Springer-Verlag, 156 p. doi:10.1007/978-1-4612-9837-3

21. Nalimov, V.V., 1974. Probabilistic Model of a Language: Relationship between Natural and Artificial Languages. Moscow: Nauka, 272 p. (in Russian).

22. Menshutkin, V.V., 2010. The Art of Modeling: Physiology, Ecology, Evolution). Petrozavodsk, 410 p. (in Russian).

23. Kurzenev, V.A. and Matveenko, V.D., 2018. Economic Growth. Saint Petersburg: Piter, 608 p. (in Russian).

24. Guzairov, M.B., Ilyasov, B.G., Zakieva, E.Sh. and Gerasimova, I.B., 2013. Cognitive Model of Life Quality Indicator Formation. Vestnik UGATU, 17(2), pp. 215-220 (in Russian). 
25. Kolmakova, I.D., Baikova, E.I. and Kolmakova, E.M., 2017. Economic and Mathematical Methods in Evaluating and Planning the Standard of Living of the Population of the Region. Regional Economics: Theory and Practice, 15(5), pp. 928-936 (in Russian).

26. Botkin, D.B., 1993. Forest Dynamics: An Ecological Model. New York: Oxford University Press, 309 p. doi:10.5860/choice.31-1511

27. Kozak, I., Menshutkin, V.V. and Klekowski, R.Z., 2003. Modelowanie Elementów Krajobrazu. Lublin: Towarzystwo Naukowe Katolickiego Uniwersytetu Lubelskiego, 190 p. (in Polish).

28. Poluektov, R.A., Smolyar, E.I., Terleev, V.V. and Topazh, A.G., 2006. Models of Plant Production Processes. Saint Petersburg: Saint Petersburg University publishing house, 396 p. (in Russian).

29. Baranov, N.S., 2014. Strategic Role of Northern Territories for Russian Economy. Society and Law, (3), pp. 297-301 (in Russian).

About the authors

Vladimir V. Menshutkin, Chief Research Associate, Institute for Regional Economic Studies, Russian Academy of Sciences (38 Serpukhovskaya St., St. Petersburg, 190013, Russian Federation), Dr. Sci. (Biology), Professor, menshutkina.n@gmail.com

Nikolai Ni. Filatov, Adviser of the Chairman of Northern Water Problems Institute, Karelian Research Center, Russian Academy of Sciences, Chief Research Associate of Northern Water Problems Institute, Karelian Research Center, Russian Academy of Sciences (50 Nevskogo St., Petrozavodsk, Russian Federation), Corresponding Member of RAS, Dr. Sci. (Geography), Professor, ORCID ID: 0000-0002-3280-4375, SPINcode: 5378-8040, nfilatov@rambler.ru

Contribution of co-authors:

Vladimir V. Menshutkin - development of the ecological-socio-economic model of the system, analysis of the obtained results on the model

Nikolai Ni. Filatov - setting of the task of ecological-socio-economic description of the White Sea and its watershed system, information support, analysis of the obtained experimental data and modellong results

All the authors have read and approved the final manuscript.

The authors declare that they have no conflict of interest. 